\title{
Long-Term Effects of a Social Intervention for Vulnerable Youth: A Register-Based Study
}

\author{
Jacob Nielsen Arendt and Mette Verner
}

\section{Introduction}

The number of children with conduct disorder problems is a growing concern in many countries. Early life problems can settle into permanent life problems with huge individual and societal costs. Young people with conduct disorder problems are likely to perform poorly in school and often face difficulties pursuing further education or employment. They often face a risk of entering a life path involving criminal activity, drug abuse, and mental health problems. The evidence on effective interventions for disadvantaged adolescents is limited, as stressed by, for example, Nobel Laureate James Heckman and co-authors (Heckman et al. 2014). Some of these young people are placed outside their homes, in foster care, although little is known about the effectiveness of foster care (e.g., Doyle 2007; Frederiksen 2012).

Multisystemic therapy (MST) is an intervention developed in the United States (US) in the 1990s by psychologist Scott Henggeler and colleagues (e.g., Henggeler et al. 1992), with a focus on 12- to 17-year-old violent juvenile offenders. It is an intensive family-based intervention based on a systemic approach: the therapist meets the child in the family home or in other familiar surroundings and is available

This chapter was written while Jacob Arendt was employed at the Danish Institute for Local and Regional Government Research (now The Danish Centre of Applied Social Science).

J. N. Arendt (訩

The ROCKWOOL Foundation Research Unit, Copenhagen, Denmark

e-mail: jar@rff.dk

M. Verner

The Danish Centre of Applied Social Science, Copenhagen, Denmark

e-mail: meve@vive.dk

N. Crato, P. Paruolo (eds.), Data-Driven Policy Impact Evaluation,

https://doi.org/10.1007/978-3-319-78461-8_14 
on call $24 \mathrm{~h}$ a day, 7 days a week. MST has been evaluated in 55 published studies based on 25 randomized controlled trials and has been adopted in more than 34 US states and 15 countries worldwide (MST Services 2017). While this is a strong evidence base, meta-analysis shows great effect heterogeneity, especially across countries. MST has been implemented in Denmark since 2003, but to date there have only been two evaluations of the Danish program. The two evaluations applied a before-after design (Greve 2006; Greve and Thastum 2008), but no effect measurement was conducted.

Because the Danish implementers of the MST intervention have gathered social security numbers for all the participants, information from various public administrative registers can be linked by Statistics Denmark.

This chapter shows how the administrative register data can be used to construct effect measurements of MST in the Danish setting. It is based on a quasiexperimental effect design that utilizes access to data for the entire Danish youth population and their parents, from the time of the children's birth. By using such register data, some of the pitfalls in the existing studies can be avoided: most are based on small samples and have self-reported outcomes, measured over short time horizons. This creates a risk of self-evaluation bias and attrition bias, which can be avoided in an analysis based on administrative register data.

The chapter is organized as follows. In the next section, previous findings on the effect of MST are summarized. This is followed in Sect. 3 by a description of the data, and a description of the constructed control group is provided in Sect. 4. Section 5 presents the effect estimates. In Sect. 6 the findings are summarized, and the section concludes with a further discussion of the benefits of using register data for impact measurements.

\section{Previous Literature}

MST was developed in the late 1980s and 1990s by psychologist Scott Henggeler and colleagues at the Family Services Research Centre at University of South Carolina. More than 55 studies have been published on the effect and implementation of MST for different subpopulations of youth.

Many of these studies have been evaluated using a randomized controlled trial. Most of these have had a limited number of participants, from 16 (Borduin et al. 1990) to 176 (Borduin et al. 1995), and with Glisson et al. (2010) being an exception, with 615 observations.

Many of the studies have shown promising results on young people's behavior, family relations, and, for example, relapse into crime for juvenile offenders (see, e.g., Curtis et al. 2004). However, a Cochrane review from 2005 concluded that the evidence was not strong enough to make final recommendations for the use of MST in preference to alternative interventions (Littell et al. 2005). However, this review 
was based on only eight randomized controlled trials, and it should be stressed that no harmful effects of MST compared with alternative interventions were found and that the overall effect was positive, but not significantly different from zero. Three possible reasons for the difference in results when compared with previous reviews (e.g., Littell 2005) are highlighted in the Cochrane review: (1) previous reviews were narrative rather than systematic; (2) the Cochrane review excluded unpublished studies; and (3) the Cochrane review did not include studies not using the intention-to-treat principle. Two Dutch studies using administrative data point toward the aforementioned self-reporting bias as another potential explanation, finding positive effects for parent- and youth-reported problem behavior but not for criminal convictions (Asscher et al. 2013, 2014). Finally, there is a large amount of effect heterogeneity across countries and across different comparison groups. In some studies, MST is compared against another specific intervention, while in others it is compared against treatment as usual. This could in itself explain the divergent results.

The most recent review of the effects of MST includes 22 studies involving 4066 young people. This study finds that, after correcting for publication bias, there is no effect of MST on specific delinquency but a small, significant, and positive effect on general delinquency, psychopathology (e.g., externalizing and internalizing behavior), and family factors (e.g., self-reported family functioning, parenting skills, or parental health). The study confirms the finding of great effect heterogeneity, e.g., showing that the effect on delinquency is larger if MST is compared with a single alternative intervention (as opposed to multiple interventions) and if it is conducted in the United States. It also shows that, although study quality matters, the use of randomized versus quasi-experimental designs did not affect the results. The fact that the results of good quasi-experimental designs do not differ from those of randomized controlled trials has been reported elsewhere (e.g., Card et al. (2015) in the case of active labor market interventions), but of course this may differ from case to case (e.g., a famous study from economics by Lalonde (1986) and elaborations on his findings, e.g., by Dehejia and Wahba (1999)).

It is worth mentioning specifically the results from Norway and Sweden because the implementation setting in these countries is likely to most closely resemble the Danish implementation setting. Both were evaluated using a randomized controlled trial. While the Norwegian studies found that MST improves participants' internalizing symptoms and decreases out-of-home placements (Ogden and Halliday-Boykins 2004), the Swedish experience found no effect of MST when compared with standard alternative social interventions (Sundell et al. 2008).

The results from the reviews-reinforced by the divergent Scandinavian findings-show the need for case-by-case evaluation, which may well be conducted using quasi-experimental designs, at the very least as a cheap first-hand examination. 


\section{Data}

The present analysis is based on information from Danish administrative register data. The relevant group of children were all observed from birth, and, furthermore, one can link information on parents to information on their children. The data come from various registers on education, health, crime, drug abuse treatment, labor market attachment, and the use of social measures. All the data were collected for administrative purposes, e.g., tax information in employment and health-care use, or for purposes of tax-financed reimbursement of health-care providers. The data are therefore considered to be highly reliable. As all Danish citizens have a unique identifier (CPR number), information from various public registers can be linked by Statistics Denmark.

The effect analysis is based on data on 436 participants who received MST at some point during the years 2007-2011. The participants were located in three municipalities (Herning, Aalborg, and Aarhus). At the time of entering MST treatment, the individuals were aged 12-17 years, and, since data are available up until 2013, the early participants can be followed up in the register data to the age of 22 .

Table 1 shows the distribution of MST participation by age and the year of entering MST treatment. The majority of the participants entered the program around the age of 14-16 years, and there is a decline in the use of MST over the period.

Table 2 presents means of selected characteristics for MST participants and all other vulnerable young people aged 12-17 years in 2007-2011. "Other vulnerable young people" are defined as young people aged 12-17 receiving alternative social measures. The social measures under consideration are out-of-home placement (institution care or foster care) and preventive measures, such as a steady contact person. These measures are all offered with reference to the Danish Act on Social Services. The act implies both that vulnerable young people have a right to receive such measures and that local municipalities must pay for them.

Table 1 Distribution of entrance into MST

\begin{tabular}{|c|c|c|c|c|c|c|c|c|c|c|c|c|}
\hline \multirow{3}{*}{$\begin{array}{l}\text { Age } \\
\text { (years) }\end{array}$} & \multicolumn{12}{|l|}{ Year } \\
\hline & \multicolumn{2}{|l|}{2007} & \multicolumn{2}{|l|}{2008} & \multicolumn{2}{|l|}{2009} & \multicolumn{2}{|l|}{2010} & \multicolumn{2}{|l|}{2011} & \multicolumn{2}{|l|}{ All } \\
\hline & Number & $\%$ & Number & $\%$ & Number & $\%$ & Number & $\%$ & Number & $\%$ & Number & $\%$ \\
\hline 12 & 5 & 4 & 7 & 9 & 5 & 6 & 4 & 5 & 0 & 0 & 21 & 5 \\
\hline 13 & 14 & 12 & 10 & 12 & 12 & 13 & 9 & 10 & 7 & 12 & 52 & 12 \\
\hline 14 & 22 & 19 & 18 & 22 & 13 & 14 & 22 & 25 & 11 & 19 & 86 & 20 \\
\hline 15 & 30 & 26 & 21 & 26 & 19 & 21 & 18 & 20 & 17 & 29 & 105 & 24 \\
\hline 16 & 30 & 26 & 16 & 20 & 26 & 29 & 20 & 23 & 13 & 22 & 105 & 24 \\
\hline 17 & 16 & 14 & 10 & 12 & 15 & 17 & 15 & 17 & 11 & 19 & 67 & 15 \\
\hline All & 117 & 100 & 82 & 100 & 90 & 100 & 88 & 100 & 59 & 100 & 436 & 100 \\
\hline
\end{tabular}


Table 2 Background characteristics of MST participants and other vulnerable young people (no corrections)

\begin{tabular}{|c|c|c|c|c|}
\hline & \multicolumn{2}{|c|}{ MST participants } & \multicolumn{2}{|c|}{ Other vulnerable young people } \\
\hline & Mean & Standard deviation & Mean & Standard deviation \\
\hline \multicolumn{5}{|c|}{ Background characteristic, treatment year } \\
\hline Age (years) & 14.97 & 1.402 & 14.88 & 1.660 \\
\hline Girl & 0.40 & 0.491 & 0.42 & 0.493 \\
\hline $\begin{array}{l}\text { First- or second-generation } \\
\text { immigrant }\end{array}$ & 0.15 & 0.357 & 0.12 & 0.321 \\
\hline Living with single parent & 0.61 & 0.487 & 0.72 & 0.448 \\
\hline $\begin{array}{l}\text { Number of children in the } \\
\text { family }\end{array}$ & 1.94 & 1.159 & 1.17 & 1.317 \\
\hline Mother social welfare recipient & 0.25 & 0.432 & 0.29 & 0.453 \\
\hline Father social welfare recipient & 0.26 & 0.437 & 0.24 & 0.425 \\
\hline \multicolumn{5}{|c|}{ Characteristics year before treatment } \\
\hline Father sentenced & 0.13 & 0.335 & 0.12 & 0.319 \\
\hline Mother sentenced & 0.03 & 0.182 & 0.05 & 0.223 \\
\hline Father in drug abuse treatment & 0.01 & 0.117 & 0.02 & 0.154 \\
\hline Mother in drug abuse treatment & 0.01 & 0.095 & 0.02 & 0.152 \\
\hline Father in psychiatric treatment & 0.21 & 0.410 & 0.20 & 0.403 \\
\hline Mother in psychiatric treatment & 0.37 & 0.117 & 0.37 & 0.482 \\
\hline Child in psychiatric treatment & 0.23 & 0.421 & 0.24 & 0.425 \\
\hline Father prescription medicine & 0.51 & 0.500 & 0.47 & 0.499 \\
\hline Mother prescription medicine & 0.65 & 0.478 & 0.64 & 0.479 \\
\hline Child prescription medicine & 0.30 & 0.457 & 0.31 & 0.462 \\
\hline Father hospitalized & 0.37 & 0.583 & 0.36 & 0.479 \\
\hline Mother hospitalized & 0.40 & 0.490 & 0.46 & 0.498 \\
\hline Child hospitalized & 0.43 & 0.495 & 0.44 & 0.497 \\
\hline $\begin{array}{l}\text { Institution care (1-2 years } \\
\text { before) }\end{array}$ & 0.05 & 0.219 & 0.26 & 0.437 \\
\hline Foster care (1-2 years before) & 0.02 & 0.126 & 0.20 & 0.399 \\
\hline $\begin{array}{l}\text { Other preventive measures } \\
\text { (1-2 years before) }\end{array}$ & 0.17 & 0.376 & 0.44 & 0.497 \\
\hline$N$ & \multicolumn{2}{|l|}{436} & \multicolumn{2}{|l|}{79,259} \\
\hline
\end{tabular}

The group means in Table 2 are given prior to any correction for background characteristics. The table shows that the two groups (MST participants and other vulnerable young people) are quite similar in terms of, for example, family background, parental characteristics, and health treatment. For instance, 13\% of the MST participants have fathers with a criminal conviction. This is true for $12 \%$ of other vulnerable young people. It is also seen that a very large share of young people in both groups have parents who were in psychiatric treatment or hospitalized in the year before they received MST or an alternative social treatment. In contrast to these results, Table 2 also shows that the share of children and young people that were placed out of the home in the years before the comparison year was 


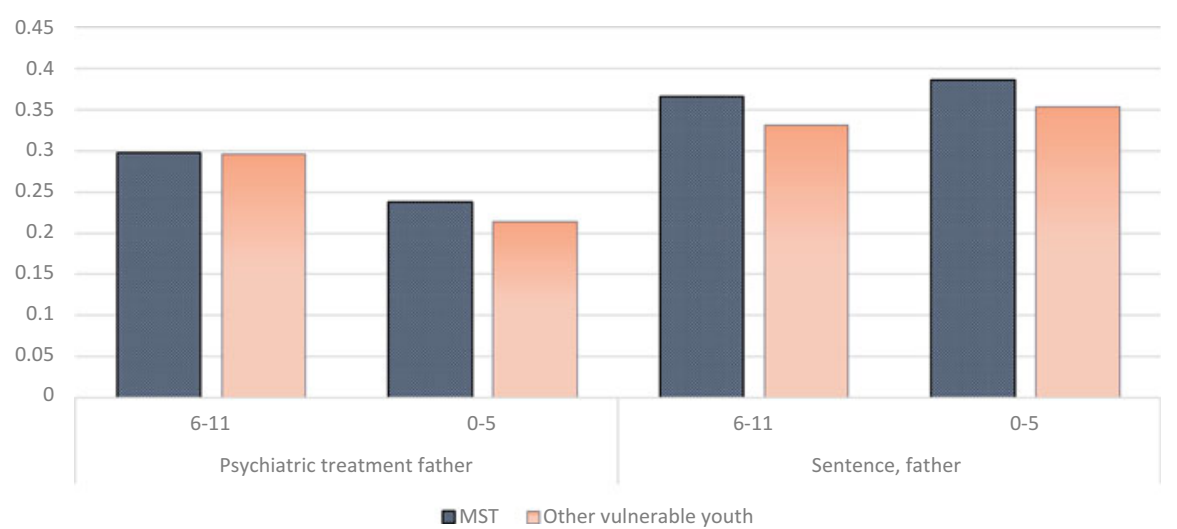

Fig. 1 Father's outcomes averaged over age groups for the child, for MST participants, and for other vulnerable young people

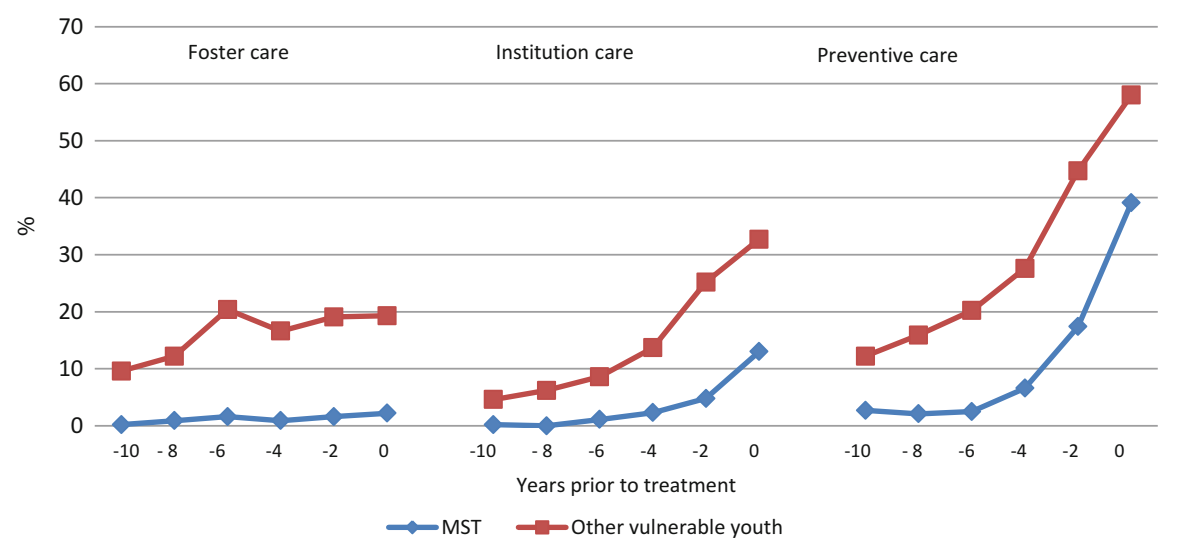

Fig. 2 Share of MST participants and other vulnerable young people receiving social measures in the years prior to treatment

substantially higher for the group of other vulnerable young people than for the MST participants. These patterns of similarity between the groups with respect to health-care usage and parental characteristics but divergence with respect to previous social interventions-are also found when looking further back in time during the children's lives. Figure 1 shows, as an example, the similarity in father's outcome for MST participants and other vulnerable young people, averaged over the years when the child was aged 0-5 years and when the child was aged 6-11 years. In contrast to this result, there is a marked difference between MST participants and other vulnerable young people with respect to the share who have previously received social treatment. This is shown in Fig. 2.

In a similar manner, the paths for some of the outcome variables of the analysis are compared in Fig. 3. Figure $3 \mathrm{a}-\mathrm{c}$ shows the share of young people that was 

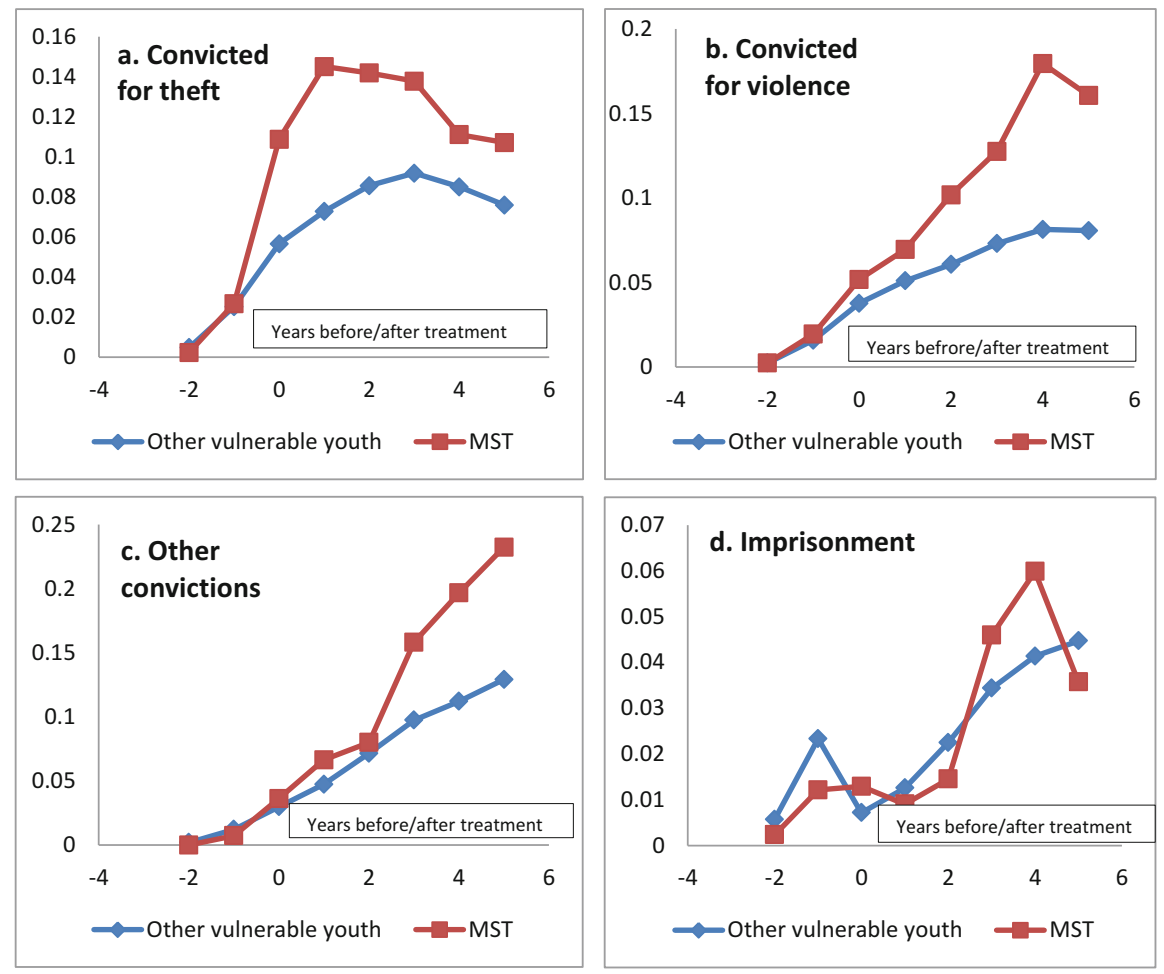

Fig. 3 (a-d) Share of young people convicted and imprisoned, by years before and after treatment

convicted in a given year. The conviction rates are shown both before and after the year of treatment. In the pretreatment period, the shares were close to zero for both groups, which is explained by the fact that the age of criminal responsibility in Denmark in the period of observation was 15 years. For all types of convictions, the rates increased after the treatment year, particularly for the MST participants. The gaps between MST participants and other vulnerable young people are as high as 10-15 percentage points. Hence, these descriptive measures do not indicate that MST has a crime prevention impact. It is, however, stressed that these numbers have not yet been corrected for differences in background characteristics between MST participants and other vulnerable young people and hence should not be interpreted causally. The corrected estimates are shown in the next section.

Figure $3 \mathrm{~d}$ presents the share of young people sentenced to imprisonment. The difference between the two groups is lower and shifts over time. As imprisonment is a sentence reserved for more severe crimes, this indicates that the higher rates of convictions for MST participants can primarily be attributed to less severe types of crime. 


\section{Method}

Evaluating an intervention such as MST is a challenge when the participants are not randomly selected from among the group of vulnerable young people. To handle the nonrandom selection, propensity score matching is applied to evaluate the effects of MST. This procedure matches each MST participant to a number of other vulnerable young people with a propensity to be treated with MST similar to that of the actual participants.

The MST participants were located in three municipalities (Herning, Aalborg, and Aarhus), and in this study, these participants are matched with similar young people in the same age group, who were living in other municipalities and receiving social measures. The matching is performed using the rich Danish register information on their childhood, health, family situation, and parents, observed every year from birth until the age at MST intervention.

As seen in the preceding section, the MST participants and other vulnerable young people are very similar, even without matching. What seems to be a major difference between the two groups is the extent to which they received social measures prior to the age at which they are compared. Prior social care is thus a key observable characteristic for which MST participants need to be matched with other vulnerable young people. Prior social care is also likely to be related to prior occurrence of conduct disorder and family problems. The design is illustrated in Fig. 4, highlighting that both the MST participants and their comparison groups are identified as vulnerable young people and therefore to a large extent similar at the outset. This study measures outcomes in the years after treatment and is able to follow MST participants and their comparison group for up to 5 years. Therefore, those who are MST participants at the age of 12 are tracked until the age of 17, and likewise those who are MST participants at the age of 17 are tracked until the age of 22. The follow-up period also depends upon the nature of the outcome, because education, crime, and employment outcomes are relevant at different ages.

The matching procedure includes register information on a very long list of variables including age, sex, family type, health-care history measures for children and their parents, criminal records, psychiatric treatment, drug abuse treatment, education of children's parents, and previous use of social measures.

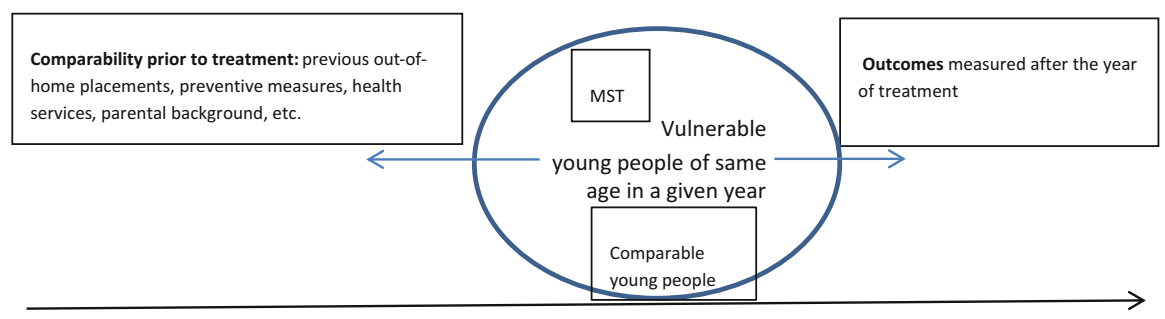

Fig. 4 Evaluation design 
Matching on this very rich set of characteristics of the child's past-including detailed annual lagged information on the social intervention history-enables a reliable comparison group to be identified for the effect evaluation (Lechner and Wunsch 2013). ${ }^{1}$

\section{Effects}

This study estimates effects of MST on outcomes measured from both shortand long-term perspectives. The outcomes include secondary education, youth education, employment, welfare dependency, criminal convictions, and use of social measures after MST treatment. All estimates are obtained by the use of matched controlled groups, as described in the previous section.

\subsection{Education Outcomes}

Compulsory schooling in Denmark is completed by a series of exams at the end of the 9th or 10th grade. The grade point average of the exam results is used as an outcome measure of secondary schooling, and the estimated effect (Table 3 ) is -0.083 and insignificant. However, a substantial share of vulnerable young people do not attend the exams, and, as is shown in Table 3, MST has a positive effect on the likelihood of attending the exam of 8.8 percentage points. It can be concluded, therefore, that although MST substantially increases the participation rate in exams, performance in the exams is not significantly affected.

From a longer-term perspective, it is relevant to see whether or not MST participants also complete the next level of education, youth education. Both branches of youth education, high school and vocational education, are taken into account. Table 4 presents the estimated effect of MST on the completion rate of youth education at various ages. For high school completion, no significant effects are found; whereas, for vocational education, the effect of MST is significantly negative at the ages of 20 and 22 years. This result is also seen in the overall completion rate of youth education, as the MST effect is -4.8 percentage points at the age of 20 and as high as -7.7 percentage points at the age of 22 .

\footnotetext{
${ }^{1}$ Technically, propensity score matching with one nearest neighbor is used. The matched control group has good balancing properties, e.g., as seen in the relative difference on matched covariates between treated and controls after matching. It never exceeds 5\%. The common support assumption is also fulfilled, and the estimates are not sensitive to the use of other matching techniques.
} 
Table 3 Effect on secondary schooling outcomes

\begin{tabular}{l|l|l}
\hline & Grade point average, mean $(\mathrm{SE})$ & Attended exam, mean rate $(\mathrm{SE})$ \\
\hline Effect & $-0.083(0.122)$ & $0.088^{* * *}(0.032)$ \\
\hline Number treated & 152 & 271 \\
\hline$N$ & 19,470 & 30,374 \\
\hline
\end{tabular}

$* p<0.1, * * p<0.05, * * * p<0.01$

Notes: Estimates from matched control groups. $\mathrm{SE}=$ standard error

Table 4 Effect on youth education completion (high school and vocational education)

\begin{tabular}{l|l|l|l}
\hline & \multicolumn{4}{l}{ Age (years), mean completion rates (SE) } \\
\cline { 2 - 4 } & 20 & 21 & 22 \\
\hline High school education & $-0.024(0.013)$ & $-0.008(0.020)$ & $0.010(0.051)$ \\
\hline Vocational education & $-0.024(0.018)$ & $0.029(0.026)$ & $-0.087^{*}(0.034)$ \\
\hline Youth education, total & $-0.048^{*}(0.020)$ & $0.021(0.033)$ & $-0.077^{*}(0.015)$ \\
\hline Number treated & 105 & 71 & 39 \\
\hline$N$ & 15,709 & 10,715 & 6771 \\
\hline
\end{tabular}

${ }^{*} p<0.1, * * p<0.05, * * * p<0.01$

Notes: Estimates from matched control groups. $\mathrm{SE}=$ standard error

\subsection{Employment and Welfare Dependency}

The effect of MST on employment and welfare dependency is calculated at every age level between the ages of 18 and 22 years. It should be noted that the number of MST participants observed declines with age due to the distribution of MST participants as described in the previous section. Welfare dependency refers to any transfer income received from the state and includes, for example, social welfare payments, unemployment benefits, and study grants. Employment is registered as any month with positive earnings. Both welfare dependency and employment are registered as a number of weeks in a given year. Table 5 shows that, on average, duration of employment of MST participants is 2-2.5 weeks less than that of young people in the comparison group at ages 20-22. This also corresponds with a higher dependency on public transfer income, amounting to 2-3 weeks per year at ages 19-22. The two lower rows of estimates in Table 5 show the separate effect on weeks with study grants and weeks on social welfare. Study grants are universal and require only admittance to an ordinary education institution. The results show that the larger share of participants dependent on public transfers is mainly due to more time on social welfare and not more time in education with study grants. 
Table 5 Effects on employment and welfare dependency

\begin{tabular}{l|l|l|l|l|l}
\hline & \multicolumn{5}{|l}{ Age (years), mean weeks (SE) } \\
\cline { 2 - 6 } & 18 & 19 & 20 & 21 & 22 \\
\hline Employment & $0.549(0.845)$ & $-0.527(0.823)$ & $-2.465^{*}(1.019)$ & $-2.048^{*}(0.953)$ & $-2.130^{* *}(0.816)$ \\
\hline $\begin{array}{l}\text { Welfare } \\
\text { dependency }\end{array}$ & $0.328(0.911)$ & $2.093^{*}(1.021)$ & $2.830(1.132)$ & $2.942^{*}(1.231)$ & $2.784^{*}(1.009)$ \\
\hline Study grants & $-1.253(0.841)$ & $-0.163(1.019)$ & $2.747(1.174)$ & $0.282(1.085)$ & $3.901(2.932)$ \\
\hline Social welfare & $2.203^{* *}(0.678)$ & $2.802^{* *}(1.065)$ & $1.023(1.329)$ & $3.935^{* *}(1.230)$ & $1.909(2.983)$ \\
\hline $\begin{array}{l}\text { Number } \\
\text { treated }\end{array}$ & 342 & 283 & 171 & 117 & 56 \\
\hline$N$ & 58,211 & 45,299 & 28,174 & 18,855 & 9252 \\
\hline
\end{tabular}

$* p<0.1, * * p<0.05, * * * p<0.01$

Note: Estimates from matched control groups. $\mathrm{SE}=$ standard error

\subsection{Crime}

As seen in the descriptive section of this chapter, another highly relevant outcome in this evaluation is crime rate. Again, individuals are followed up to 5 years after the intervention year. Table 6 shows that most of the estimated effects, and in particular all significant effects, are positive. This means that MST participation increases the probability of having been convicted of a crime by up to 9.1 percentage points. No significant effects are found on the probability of being sentenced to imprisonment.

MST was originally developed as a measure directed toward criminal young people and has previously been shown to be effective in reducing young people's crime rates. Therefore, the sample is reduced to focus on young people who were convicted before the year of intervention, and similar effect estimates can be calculated for this subgroup. These are presented in Table 7. In this case, most effect estimates are insignificant. However, in the case of violence during the first year after the intervention, a significant negative effect of -5.5 percentage points is found, and, similarly, for imprisonment, the effect is -2.8 percentage points. This

Table 6 Effects on criminal convictions and prison sentencing

\begin{tabular}{l|l|l|l|l|l}
\hline \multirow{2}{*}{} & \multicolumn{4}{l}{ Years after treatment, mean conviction rates (SE) } \\
\cline { 2 - 6 } & $t+1$ & $t+2$ & $t+3$ & $t+4$ & $t+5$ \\
\hline Violence & $-0.003(0.014)$ & $0.0287(0.015)$ & $0.047 * * *(0.009)$ & $0.091^{* * *}(0.009)$ & $0.075(0.051)$ \\
\hline Theft & $0.057 * * *(0.016)$ & $0.043^{*}(0.019)$ & $0.040^{*}(0.018)$ & $0.009(0.024)$ & $0.048(0.042)$ \\
\hline $\begin{array}{l}\text { Other } \\
\text { convictions }\end{array}$ & $0.008(0.013)$ & $-0.002(0.006)$ & $0.038^{*}(0.018)$ & $0.049 *(0.024)$ & $0.104(0.059)$ \\
\hline Imprisonment & $-0.003(0.005)$ & $-0.007(0.007)$ & $0.002(0.013)$ & $0.011(0.014)$ & $-0.005(0.026)$ \\
\hline Number treated & 421 & 411 & 386 & 331 & 275 \\
\hline$N$ & 25,282 & 20,933 & 15,974 & 11,266 & 6835 \\
\hline
\end{tabular}

$* p<0.1 . * * p<0.05 . * * * p<0.01$

Notes: Estimates from matched control groups. $\mathrm{SE}=$ standard error 
Table 7 Criminal convictions and prison sentences, for individuals with previous convictions

\begin{tabular}{l|l|l|l|l|l}
\hline \multirow{2}{*}{} & \multicolumn{4}{l}{ Years after treatment, mean conviction rates (SE) } \\
\cline { 2 - 6 } & $t+1$ & $t+2$ & $t+3$ & $t+4$ & $t+5$ \\
\hline Violence & $-0.055^{* * *}(0.234)$ & $0.002(0.015)$ & $-0.005(0.063)$ & $-0.008(0.077)$ & $0.0346(0.091)$ \\
\hline Theft & $0.018(0.020)$ & $0.021(0.0422)$ & $0.064(0.059)$ & $-0.077(0.045)$ & $0.004(0.077)$ \\
\hline $\begin{array}{l}\text { Other } \\
\text { convictions }\end{array}$ & $-0.020(0.172)$ & $-0.014(0.021)$ & $0.009(0.066)$ & $-0.044(0.087)$ & $0.039(0.101)$ \\
\hline Imprisonment & $-0.028 * *(0.131)$ & $-0.006(0.034)$ & $-0.043(0.046)$ & $-0.031(0.046)$ & $-0.031(0.064)$ \\
\hline Number treated & 71 & 65 & 56 & 39 & 26 \\
\hline$N$ & 3448 & 3224 & 2794 & 2312 & 1731 \\
\hline
\end{tabular}

$* p<0.1 . * * p<0.05 . * * * p<0.01$

Notes: Estimates from matched control groups. $\mathrm{SE}=$ standard error

suggests that, in this subsample of young people with previous criminal convictions, MST has reduced crime rates.

\subsection{Social Measures}

In a similar manner, the effect of MST on subsequent use of social interventions, in terms of out-of-home placement and preventive measures, can also be analyzed. From Table 8, it is seen that only in the first year after treatment is the number of days in out-of-home placement lower for the MST group than for the control group. However, caution should be taken when interpreting these effects. Because part of the control group is in out-of-home placement, which usually lasts more than a year, the control group will on average tend to have a higher out-of-home placement prevalence in the following year. For other preventive measures, the MST group receives significantly fewer days than the control group throughout the observation period, with the magnitude of the difference ranging between 15 and 50 days.

\section{Discussion}

This chapter has presented an example of how to use administrative register data to obtain new knowledge about the effectiveness of social interventions. It has examined the case of a small-scale social intervention-multisystemic treatment (MST) — which is targeted toward vulnerable young people and which has been 


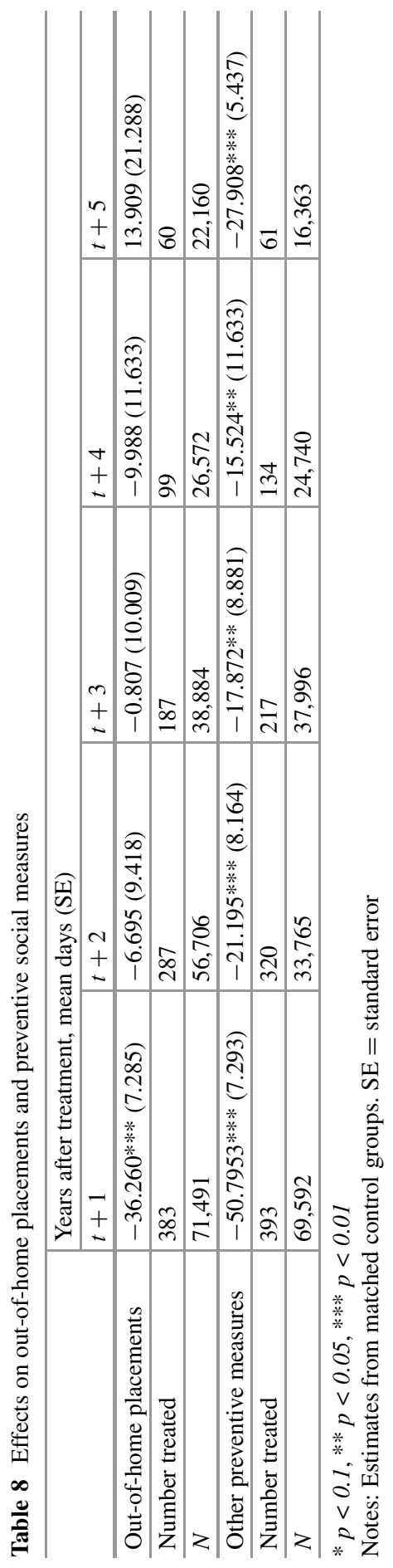


applied to young people with conduct disorder problems and juvenile offenders. The intervention has been evaluated numerous times in various countries using randomized controlled trials but often with highly divergent results across target groups and across countries.

MST has been used in Denmark for more than 13 years, but its effect there has never been evaluated. The gold standard for effect evaluation is a randomized controlled trial. However, randomized controlled trials are expensive and are often difficult to conduct because of resistance from social workers and decision-makers when it comes to social interventions. But randomized controlled trials are not without other limitations, both with respect to potential contamination of control and treatment groups and because they are often based on small-scale interventions that are sometimes difficult to extrapolate to real-world settings. They are often also dependent upon survey measurements of outcomes, with problems of attrition over time and measurement error or self-reporting biases.

This is not to say that randomized controlled trials are not worth pursuing, but alternatives might be worth pursuing in difficult cases. Administrative register data are a hugely valuable source of information which, applied in the right way, can provide new insights at relatively low costs. This chapter has shown how to obtain effect measures, 13 years after the first use of MST in Denmark. The approach benefited from access to life-cycle data on children and their parents and the opportunity to track children and young people over time with very limited attrition and measurement error. The possibility that the estimates may have biases cannot be excluded, but it seems very unlikely that the biases are large enough to remove the negative effects documented.

\section{References}

Asscher JJ, Deković M, Manders WA et al (2013) A randomized controlled trial of the effectiveness of multisystemic therapy in the Netherlands: post-treatment changes and moderator effects. J Exp Criminol 9:169-187

Asscher JJ, Deković M, Manders WP et al (2014) Sustainability of the effects of multisystemic therapy for juvenile delinquents in the Netherlands: effects on delinquency and recidivism. $\mathrm{J}$ Exp Criminol 10(2):227-243

Borduin CM, Henggeler SW, Blaske DM et al (1990) Multisystemic treatment of adolescent sexual offenders. Int J Offend Ther Comp Criminol 35:105-114

Borduin CM, Mann BJ, Cone LT et al (1995) Multisystemic treatment of serious juvenile offenders: long-term prevention of criminality and violence. J Consult Clin Psychol 63:569-578

Card D, Kluve J, Weber A (2015) What works? A meta analysis of recent active labor market program evaluations. IZA Discussion Paper No 9236. Institute of Labor Economics, Bonn

Curtis NM, Ronan K, Borduin CM (2004) Multisystemic treatment: a meta-analysis of outcome studies. J Fam Psychol 18(3):411-419 
Dehejia RH, Wahba S (1999) Causal effects in nonexperimental studies: reevaluating the evaluation of training programs. J Am Stat Assoc 94(448):1053-1062

Doyle JJ (2007) Child protection and child outcomes: measuring the effects of foster care. Am Econ Rev 97(5):1583-1610

Frederiksen S (2012) Empirical essays on placements in outside home care. PhD thesis. In: Department of Economics and Business. Aarhus University, Aarhus

Glisson C, Schoenwald SK, Hemmelgarn A et al (2010) Randomized trial of MST and ARC in a two-level evidence-based treatment implementation strategy. J Consult Clin Psychol 78(4):537-550

Greve M (2006) Resultatevaluering af multisystemisk terapi i Danmark 2004-2007. Delrapport. Servicestyrelsen \& Jysk Socialforsknings- og Evalueringssamarbejde, Højbjerg, p 1

Greve M, Thastum M (2008) Resultatevaluering af multisystemisk terapi i Danmark 2004-2007. Delrapport. Servicestyrelsen \& Jysk Socialforsknings- og Evalueringssamarbej-de, Højbjerg, p 2

Heckman JJ, Humphrey JE, Kautz T (2014) The myth of achievement tests: the GED and the role of character in American life. University of Chicago Press, Chicago

Henggeler SW, Melton GB, Smith LA (1992) Family preservation using multisystemic therapy: an effective alternative to incarcerating serious juvenile offenders. J Consult Clin Psychol 60:953961

Lalonde J (1986) Evaluating the econometric evaluations of training programs with experimental data. Am Econ Rev 76:604-620

Lechner M, Wunsch C (2013) Sensitivity of matching-based program evaluations to the availability of control variables. Labour Econ 21:111-121

Littell JH (2005) Lessons from a systematic review of effects of multisystemic therapy. Children and Youth Serv Rev 47:445-463

Littell JH, Popa M, Forsythe B (2005) Multisystemic therapy for social, emotional, and behavioral problems in youth aged 10-17. The Cochrane Database of Systematic Reviews 4:CD004797

MST Services (2017) Multisystemic therapy: research at a glance - published MST outcome, implementation and benchmarking studies. MST Services, Mount Pleasant

Ogden T, Halliday-Boykins CA (2004) Multisystemic treatment of antisocial adolescents in Norway: replication of clinical outcomes outside of the US. Child Adolesc Ment Health 9(2):77-83

Sundell K, Hansson K, Lofholm C et al (2008) The transportability of multisystemic therapy to Sweden: short-term results from a randomized trial of conduct-disordered youths. J Fam Psychol 22(4):550-560

Jacob Nielsen Arendt ( $\mathrm{PhD}$, Economics) is research leader at the Rockwool Foundation research unit. He was professor and program coordinator for Labor Market and Education at KORA from 2007 to 2011, and was associate professor in Health Economics at University of Southern Denmark from 2006 to 2011. His research focuses upon quasi-experimental impact evaluation and costbenefit analysis of public interventions. He has expertise in the use of Danish administrative register data based on more than 20 years of use. Jacob has conducted research on social inequalities in health, the impact of financial aid for education, active labor market policy, and most recently on early child care interventions. He has published in well-renowned journals such as the Journal of Health Economics, Empirical Economics, and the Journal of Human Capital as well as more than 30 research reports and book chapters for Danish ministries and national boards.

Mette Verner is a research professor in economics at KORA, Danish Institute for Local and Regional Government Research, and she is also part of TrygFonden's Centre for Child Research at Aarhus University. Her work is focused on quantitative impact evaluations of policies and interventions directed toward families, children, and youth. Furthermore, within this area, Mette 
Verner has specialized in cost-benefit analysis using survey and register-based data. In addition she has substantial experience within the field of empirical labor market and social research where her specialization is within the field of gender equality and family-friendly policies.

Open Access This chapter is licensed under the terms of the Creative Commons Attribution 4.0 International License (http://creativecommons.org/licenses/by/4.0/), which permits use, sharing, adaptation, distribution and reproduction in any medium or format, as long as you give appropriate credit to the original author(s) and the source, provide a link to the Creative Commons license and indicate if changes were made.

The images or other third party material in this chapter are included in the chapter's Creative Commons license, unless indicated otherwise in a credit line to the material. If material is not included in the chapter's Creative Commons license and your intended use is not permitted by statutory regulation or exceeds the permitted use, you will need to obtain permission directly from the copyright holder.

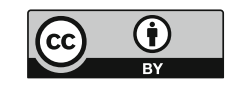

